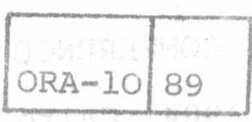

\title{
A HEURISTIC PROJECT SCHEDULING APPROACH
}

M.A.EI Kadeem M.A.EI Dardiry S.A.Moussad

ABSTRACT

This work documents a conventionel heuriatic project scheduling apkoacs for solving multiple resource-constrained project geheduling problems.

Thus, the Intent of this paper, is to demonstrate the design aspects of a auggeated heuriatic approsch for resource leveling to projects scheduling undex limited regource availabilities.

The typical characteristics of the suggested heuristic procedure are:

a- Resource leveling program utilizeg the parallel approach.

b- Multi-resource congtrained with variable resource availablities.

co Make use of different priority miles

d- Possibility of activity oplitting

Test problem results are repreaented

- Prof. and Head of Prod. Eng. Dept., Alexandria University. (0) Assist. Prof., Prod. Eng. Dept., Alexandria University. 000 Assigt. Lecturer, Prod. Eng. Dept., Alexandria University. 


\section{Introduction}

The absence of practical mathematical solutions for solving the regource-constrained project scheduling problems, led to developing and proposing many heuristic al.gord thms.

However, there is considerable conflicting evidence regarding the relative merit of such heuristic algorithms, owirg to their nature, which is usually "tallor made" to fit a particular set of conditions.

Obviously, heuristic procedures for resolution of project scheduling problems, are mainly problemoriented. Several anong them are proprietory programs on which no detailed information concerning internal logical structure ia available.

Hence, a suggested conventional heuristic model, for solving multi-resource constrained project scheduling problems, will be presented.

This suggested heuristic model incorporates a modification through additional capablities and generalization of mainly two heuristic models, viz.; SPAR-1 hodel $[1,2,3]$ and PROJACS Model $[5]$. 
The following discussion demostrates the main ideas and features of the suggested heuristic model.

The main feature of the suggegted heuristic program is allocation of resources on a period-by-period basis to some subset of the available activities for scheduling - those activities whose early start dates have been reached and their predecessor activities have been completed.

The project is treated as series of discretetime intervals for each of which, resource availabilities are specified and the availability set of activities ready for scheduling process is defined. Hence, the scheduling process proceeds in a manner such that, schedule as many of the available activities as are possible and deferring remeinder for consideration in a subsequent time-interval.

The essential heuristics (priority rules) are predefined. These heuristic are those that determine which activities shall be scheduled and which shall be postponed in any period. Furthermore, heuristics or priorities are evaluated dymamically, within each timeinterval, from properties of the considered activities and without detalled regard for the rest of the project. The heuristic incorporated in the suggested 
model may be listed as follows :

Select the activity which

$\S$ has the earliest start time

$\S$ has the minimum late strart time

$\S$ has the minimum early finish time

$\S$ has the minimum late finish time

$\S$ has the least total float

$\S$ has the shortest duration

Other heuristic can be easily involved into such model.

Moreover, the suggested heuristic approach offers many computation capabilities. These capabilities can be stated as follows :

a- Scheduling Policy. There are two general policies for scheduling, namely, a fixed-time scheduling and a fixed-resource scheduling.

In fixed-time scheduling approach, priority is given to meeting target dates, even if this entails providing additional amount of resources. With fixed-resource scheduling approach, priority is given to staying within estimated levels of available resources, even if this entails delaying certain activities.

b-Mult-Resource Constrained. The resource scheduling process is laid out to manipulate Multi-Resource Constrained considerations. More than three different types of resources 
can be defined as resources to be allocated. The word resources Is not sufficiently descriptive, therefore, labels, parameters and attributes are needed. As mentioned before, many kinds of resources can be used in the scheduling process. Each resource type can be treated as one of the following two resource categories:

$\$$ the carried-forward (reusable) resource type on which the resource used by an activity is available for another activity as soon as the first one has finished using it.

$\$$ the used-by-job resource type on which the resource used by an activity is no longer available for any other activity.

To carry out resource analysis, the availability of resources must be defined in straight forward way. The level of resource availability is variable. This is expressed as a resource availability vector which represents changes in level of resource along the considexed planning horizon. Thus, the availabilities of any resource kind may vary throughout the time. These changes are based on date, $i . e .$, at a given date, the availability takes on a new value which remains until the following change. With reusable resources (human, $\mathrm{m} / \mathrm{cs}$......etc.), under 
utilization cannot be carried forward to the next time period, as in the case of used by job resources (financial or material resources). Such resource feature brings into consideration, the periodic updating of resource availability vectors, which determines the changes in resource levels as a result of resources which can be passed from one time period to the next.

c- Possibility of Activity Splitting. The basic issue, of the suggeste heuristic scheduling algorithm, involves pre-emptive capability for non-critical activities. In this way, splitting of an activity can be done for one time or more and this is allowed in the case where resource limits are extremely tight.

d- Critique Resorts. There are four parameters that are introduced in the suggested heuristic algorithm, namely the secondary resource availability levels, the allowed delay, the dynamic float and the critical slack. Each activity can be scheduled on the basis either of primary resource availability levels (as mentioned before) or on a set of secondary availability levels correspond to the alternate use of resources than those primarily assigned.

The allowed delay is defined as the difference project target completion date and the completion date obtained from CPM-conventional time duration. 
As the criticiam of an activity must be songidexed as a dynamic value, the dynamic float reprasents the expected delay (in the mathematical sense) in t'e completion of an activity without violating the constraint of project completion target date.

Critical slack Is a predefined parar ater which determines a significant value of the dynamic float of activities.

In $F_{18}$ (I) and FIg. (2) the above mentioned definitions axe clarified and demostrated.

\section{The Heuristic Model Description}

Whe workings of the proposed heuristic model

will be explained by tracing through the main flow chart representation shown in Fig. ( 3 ).

Nevertheless, the model can be described in terms of the following majox modules:

\section{Network and Resource Description Modules}

The firat phase of the system execution, is the preparatory phase. During this phase, the network layout is described in terms of a set of input data parameters. Also, both resource requirements and availabilities, are described In mimilar way. Hence, the calculation of the conventional critical path configurationg is processed and directed through the considered modules. 


\section{Activities Ranking Module}

The subsequent phase in the considered heuristic program is an activity ranking phase. Evidently, the set of activities scheduled to start execution at any time instant are ordered according to a predefined priority rule. Thus, every activity is assigned a rank according to its prifority and should be handled according to its associated preference.

\section{Resource Assignment Module}

Having ordered the set of activities to be handled, each activity is dealt with in turn. An activity cannot start execution if any of its resource requirements is not satisfied.

Normally, when an activity asks for resources, the system attempts to fulfill its demand from the primary level of resource avallability. If the primary level is not sufficient, an attempt to fulfill the remaining shortage from the secondary level of resource availabilities is done.

If the remaining shortage problem persists, the system will delay the activity so that it would start execution alter one time slice. However, an exception to this occurs if the activity is critical, i.e., it has no more dynamic float. In this case, the system L.. 
look among the more prior activities handled at

the instant, in search for one or more non-critical

ties which would possibly be delayed. This subset

thities are reranked in view of a specified

ng rule, where they are dealt with from the least

activity to the most prior activity.

unber of activities, whose resource requirements

compansate the shortage quantity, is delayed one

stree, i.e., pre-emption would occur, and hence all

esources assigned to them are disengaged and allocated nging critical activity.

A. worst case may occur if, the last resort, of

ig non-critical activities having higher priority

60 a fallure. In this situation, the hanging

Soal sctivity is delayed one time slice and conse-

$51 y$ postponing the start time of execution of all

Hubsequent activities.

Thus, the project completion time will be delayed toine slice. 


\section{A_Cosge_Example}

To investigate the applicability of the suggested heuristic model. Consider the project of eight activities shown in Fig. ( 4 ). There are three different type of resources of variable availabilities along the planning horizon of 20 time periods. Moreover, these variable availabilities of resources are categorized as primary resource availabilities and secondary resource availabilities.

The conventional CPM analysis yields to a schedule which has a total duration of 14 time perlods.

Experimentation with the suggested heuristic model and considering the earliest start time as a priority rule, yields to the schedule shown in Fig. ( 5 ). This schedule has a completion time $=16$ time periods . A summary of the input data with the output results is exhibited in Table (I).

On the other hand, a similar and equivalent results, has been obtained in case of using the shortest duration as an alternative priority rule. The results are typical with the exception of both periods 3 and 4 . In period 3 the acheduled activities were $(2-3),(2-4)$ and $(1-3)$. While, in period 4, the scheduled activities were (2-4) and $(1-3)$.

By considering the CPM activity float as a priority rule the schedule shown in Fig. (6) was obtained for the same project example. Table ( 2 ) exhibits the input data and reaults obtained from implementing the suggested heuristic model in the considered situation. 


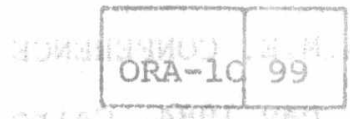

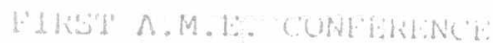
$29-32$ ilay teps, :1110

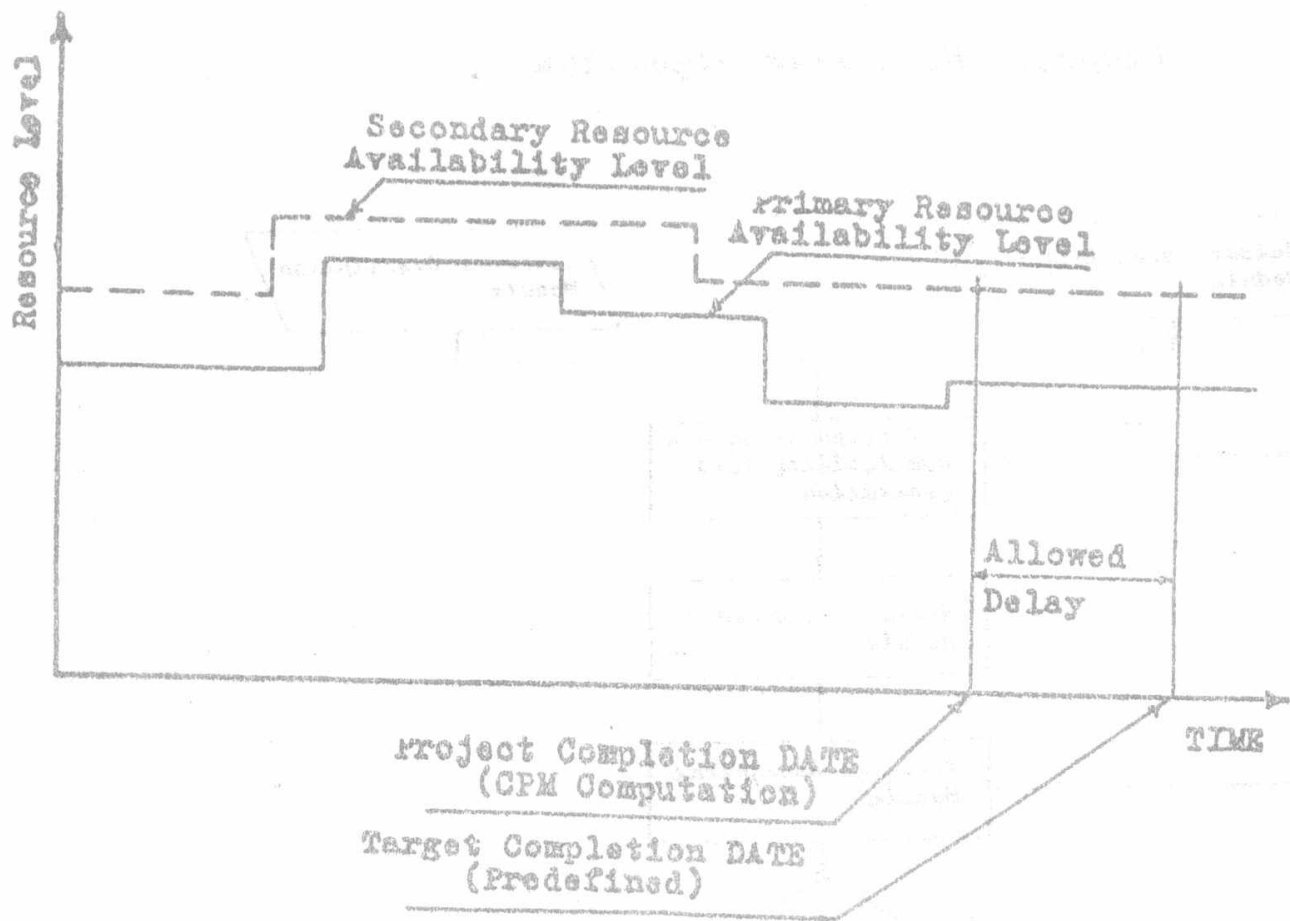

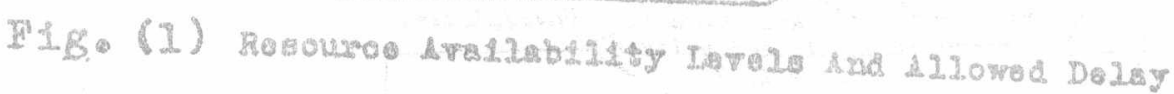

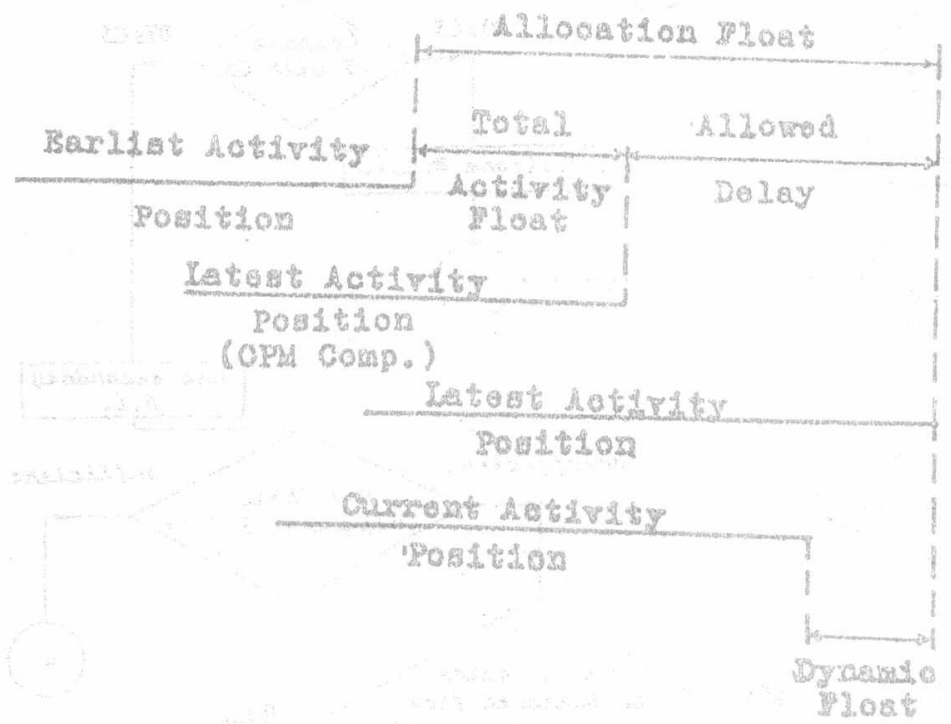

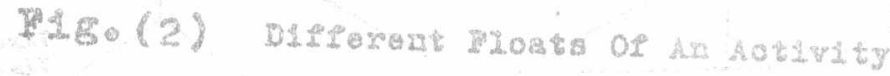


\begin{tabular}{|l|l|}
\hline ORA-10 & 100 \\
\hline
\end{tabular}

LIKL'L A.M.L. CONELERLNCE'

29-31 May 1984, Cairo

Fig. ( 3 )

Proposed Hewlstle Algoulthe

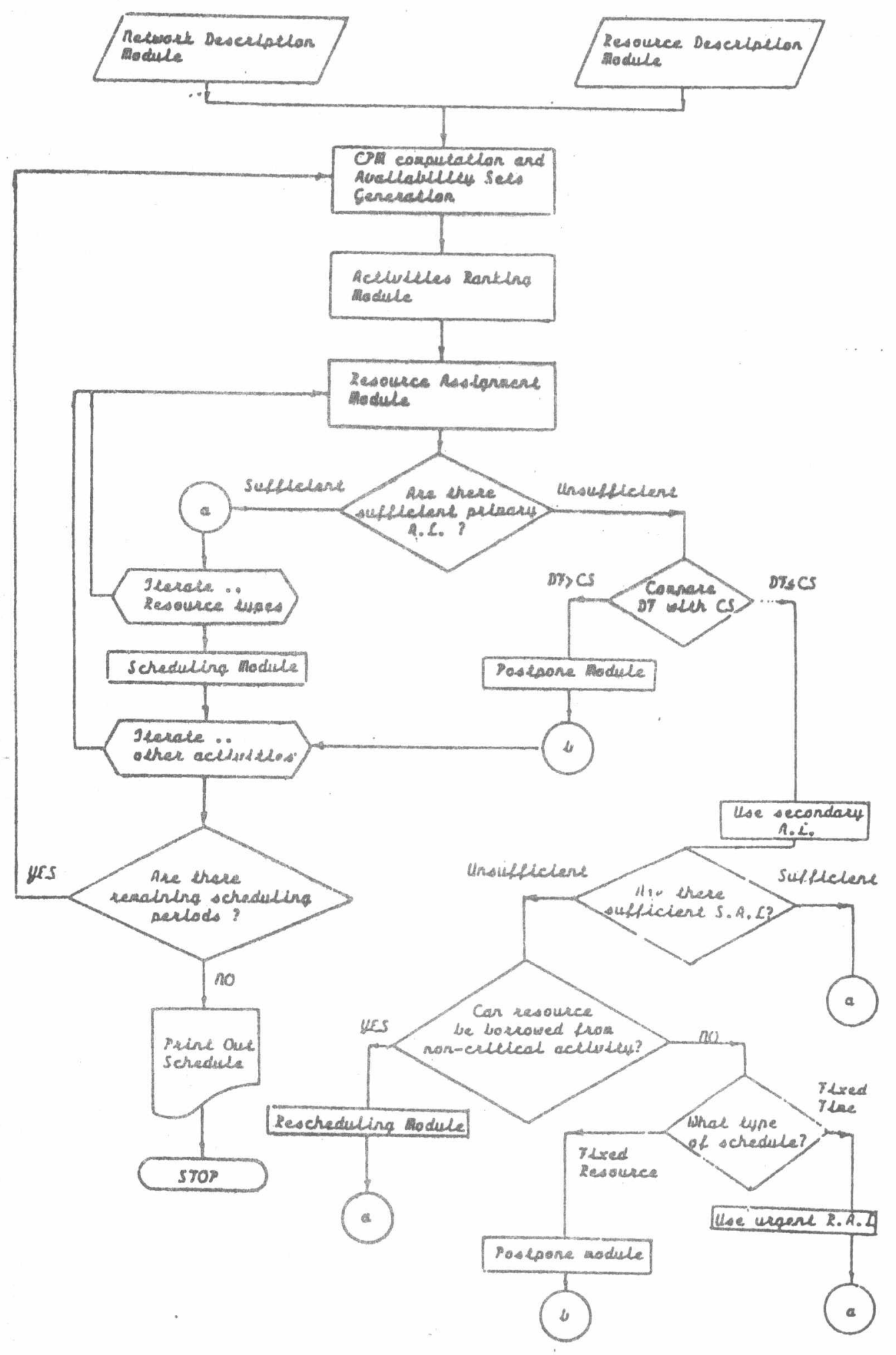




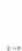
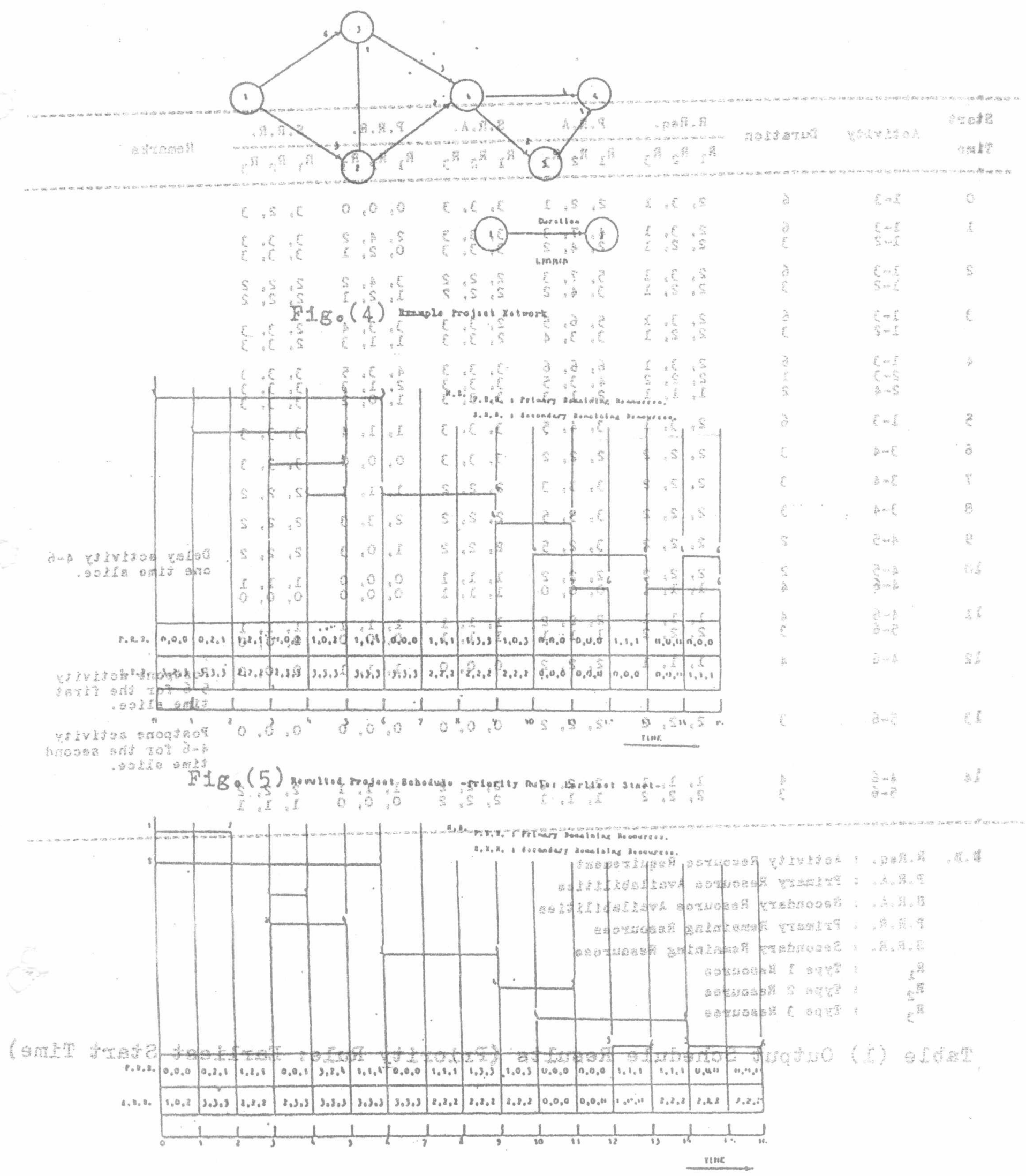

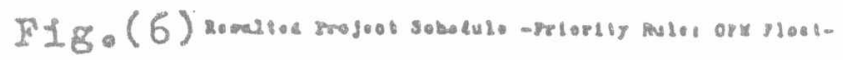




\begin{tabular}{|c|c|c|c|c|c|c|c|c|}
\hline Start & lotiv1.ty & Duration & 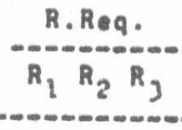 & $\begin{array}{c}P \cdot R \cdot A \\
R_{1} R_{2} R_{3}\end{array}$ & \begin{tabular}{l} 
S.R.A. \\
\hdashline$R_{1} R_{2} R_{3}$
\end{tabular} & $\begin{array}{l}\text { P.R.R. } \\
R_{2} R_{p}, R_{3}\end{array}$ & $\begin{array}{l}S . R \cdot R . \\
R_{1}, R_{2}, R_{9}\end{array}$ & Remerks \\
\hline 0 & $2-3$ & 6 & $2,3,1$ & $2,2,1$ & $3,3,3$ & $0 ; 0,0$ & $3,2,3$ & \\
\hline 2 & $\begin{array}{l}1-3 \\
1-2\end{array}$ & $\begin{array}{l}6 \\
3\end{array}$ & $\begin{array}{lll}2 & 3 \\
2 & 2 & 1 \\
2 & 1\end{array}$ & $\begin{array}{ll}4,7 & 7 \\
2, & 4,2\end{array}$ & $\begin{array}{ll}3 ; & 3, \\
3 & 3\end{array}$ & $\begin{array}{lll}2, & 4, & 2 \\
0, & 2, & 1\end{array}$ & 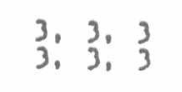 & \\
\hline 2 & $\begin{array}{l}1-3 \\
1-2\end{array}$ & $\begin{array}{l}6 \\
3\end{array}$ & $2,3, \frac{1}{2}$ & $\begin{array}{lll}5, & 7, & 3 \\
3 & 4 & 2\end{array}$ & $\begin{array}{lll}2, & 2, & 2 \\
2, & 2, & 2\end{array}$ & 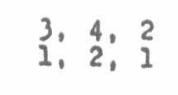 & $\begin{array}{lll}2, & 2, & 2 \\
2, & 2, & 2\end{array}$ & \\
\hline 3 & $\begin{array}{l}1-3 \\
1-2\end{array}$ & $\begin{array}{l}6 \\
3\end{array}$ & 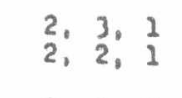 & 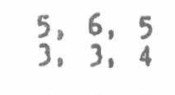 & $\begin{array}{l}2,3,3 \\
2,3 ;\end{array}$ & $\begin{array}{lll}3 ; & 3 ; & 4 \\
1 ; & 1 ; & 3\end{array}$ & $\begin{array}{lll}2, & 3, & 3 \\
2, & 3, & 3\end{array}$ & \\
\hline 4 & $\begin{array}{l}2-3 \\
2-3 \\
2-4\end{array}$ & $\begin{array}{l}6 \\
1 \\
2\end{array}$ & $\begin{array}{lll}2, & 3, & 1 \\
2, & 2, & 2 \\
1, & 1, & 1\end{array}$ & $\begin{array}{l}6,6,6 \\
4: 3,5 \\
2,3,3\end{array}$ & $\begin{array}{ll}3: & 3: \\
3 ; & 3 ; \\
3 ; & 3 \\
3 & 3\end{array}$ & $\begin{array}{lll}4: & 3, & 5 \\
20 & 1, & 3 \\
1, & 0, & 2\end{array}$ & $\begin{array}{l}3,3,3 \\
3: 3,3,3 \\
3,3,3\end{array}$ & \\
\hline 5 & $1-3$ & 6 & $2,3.1$ & $3,4,5$ & $3,3,3$ & $1,1,4$ & $3,3,3$ & \\
\hline 6 & $3-4$ & 3 & $2,2,2$ & $2,2,2$ & $3,3,3$ & $0,0,0$ & 3. 3.3 & \\
\hline 7 & $3-4$ & 3 & $2,2,2$ & $3,3,3$ & $2,2,2$ & 1. 1,1 & $2,2,2$ & \\
\hline 8 & $3-4$ & 3 & $2,2,2$ & $3,5,5$ & $2,2,2$ & $2,3,3$ & $2,2,2$ & \\
\hline 9 & $4-5$ & 2 & $2,2,2$ & $3,2,5$ & $2,2,2$ & $1,0,3$ & $2,2,2$ & $\begin{array}{l}\text { Delay activity } 4-\hbar \\
\text { one time slice. }\end{array}$ \\
\hline 10 & $\begin{array}{l}4-5 \\
4-6\end{array}$ & 2 & $\begin{array}{lll}2, & 2, & 2 \\
1, & 1, & 1\end{array}$ & $\begin{array}{lll}2 & 2 & 2 \\
0 & 0 & 0\end{array}$ & $\begin{array}{l}1,1,1 \\
1,1\end{array}$ & $\begin{array}{lll}0, & 0 & 0 \\
0 & 0 & 0\end{array}$ & $\begin{array}{lll}1, & 1 & 1 \\
0 & 0, & 0\end{array}$ & \\
\hline 211 & $\begin{array}{l}4-6 \\
5-6\end{array}$ & $\begin{array}{l}4 \\
3\end{array}$ & $\frac{1}{2}, \frac{1}{2}, \frac{2}{2}$ & $\begin{array}{lll}2, & 2 & 2 \\
1 & 1 & 1\end{array}$ & $\begin{array}{l}1,1 \\
1,\end{array}$ & $\begin{array}{lll}1 & 1 & 1 \\
0 & 0 & 1 \\
0 & \end{array}$ & $\begin{array}{lll}1 & 1 \\
0 & 0 & 1 \\
0 & 0\end{array}$ & \\
\hline 12 & $4-6$ & 4 & $1,1,1$ & $2,2,2$ & $0,0,0$ & $1,2,1$ & $0,0,0$ & $\begin{array}{l}\text { Postpone activity } \\
5-6 \text { for the first } \\
\text { time ollce. }\end{array}$ \\
\hline 13 & $5-6$ & 3 & $2,2,2$ & $2,2,2$ & $0,0,0$ & $0,0,0$ & 0.0 .0 & $\begin{array}{l}\text { Postpone activity } \\
4-6 \text { por the second } \\
\text { time allce. }\end{array}$ \\
\hline 24 & $\begin{array}{l}4-6 \\
5-6\end{array}$ & 3 & $\frac{1}{2}, \frac{1}{2} ; \frac{1}{2}$ & $\begin{array}{l}2,2 \\
1\end{array} i_{1} \cdot 2$ & $\begin{array}{lll}2, & 2, & 2 \\
2, & 2, & 2\end{array}$ & $\begin{array}{lll}1 & 1 \\
0 & 0 & 1 \\
0 & 0 & 0\end{array}$ & $\begin{array}{lll}2, & 20 \\
1, & 1, & 1\end{array}$ & \\
\hline
\end{tabular}

M. R. Req. : Aetivity Regource Requirement

P,R.A. : Primery Reource Ava1dabil1t10a

B.R.A. : Secondary Resource Avallabllitieo

P.R.R. : Primary Remalning Remourees

\$.R.R. \& Secondary Rearining Resourea

R I : Type 1 Resoures

$R_{2}$ : PYpe 2 Resouroe

$R_{3}$ : Typo 3 Rasourae

Table (I) Output Schedule Resulta (Priority Rule: Earliest Start Time) 


\begin{tabular}{|c|c|c|c|c|c|c|c|c|}
\hline $\begin{array}{l}\text { Start } \\
\text { Time }\end{array}$ & Activity & Duration & $\begin{array}{ll}R \cdot R e q . \\
R_{1} & R_{2} R_{3}\end{array}$ & $R_{2} R_{2} R_{3}$ & $\frac{S \cdot R_{0} A}{R_{1} R_{2}} R_{3}$ & $\frac{R \cdot R \cdot R}{R_{2} R_{2} R_{3}}$ & $\begin{array}{lll}S \cdot R \cdot R \\
R_{1} & R_{2} & R_{3}\end{array}$ & Remarka \\
\hline 0 & $\begin{array}{l}1-2 \\
1-3\end{array}$ & 3 & $2,2,3$ & $0,0,0$ & $3,3,3$ & $\begin{array}{lll}0, & 0, & 0 \\
0 & 0 & 0\end{array}$ & $3 ; 3,3$ & \\
\hline 1 & $\begin{array}{l}1-2 \\
1-1\end{array}$ & $\frac{3}{6}$ & $2,2,1$ & $\begin{array}{l}4,4,3 \\
2,5,2\end{array}$ & $3,3,3$ & $\begin{array}{l}2,5, i \\
0,2, i\end{array}$ & $\begin{array}{ll}3,3, & 3 \\
3, & 3,\end{array}$ & \\
\hline 2 & $\begin{array}{l}3-2 \\
2-3\end{array}$ & $\frac{3}{6}$ & $\begin{array}{ll}2,2,2 \\
2, & 30 \\
2 & 1\end{array}$ & $\begin{array}{l}5,7,3 \\
3,5,2\end{array}$ & $\begin{array}{ll}2, & 2,2 \\
2, & 2,2\end{array}$ & $\begin{array}{l}3,5,2 \\
1,2,1\end{array}$ & $\begin{array}{l}2,2,2 \\
2,2,2\end{array}$ & \\
\hline 3 & $\begin{array}{l}1-3 \\
2-3 \\
2-4\end{array}$ & $\begin{array}{l}i \\
i \\
2\end{array}$ & 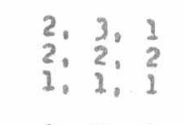 & $\begin{array}{l}5,6,5 \\
3,3 ; \\
3,1,2\end{array}$ & $\begin{array}{l}2,3,3 \\
2,3 ; \\
2,3, \\
3\end{array}$ & 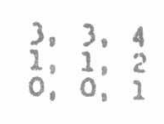 & $\begin{array}{lll}2, & 3, & 3 \\
2 & 3 & 3 \\
2 & 3 & 3\end{array}$ & \\
\hline 4 & $\begin{array}{l}?-3 \\
2-4\end{array}$ & $\begin{array}{l}6 \\
2\end{array}$ & $\begin{array}{l}2,3, \\
1,1 \\
1,1\end{array}$ & $\begin{array}{l}6,6,6 \\
4,3,5\end{array}$ & $3,3,3$ & $\begin{array}{l}\text { 4. 3, } 5 \\
3,2,4\end{array}$ & $3,3,3$ & \\
\hline 5 & $2-3$ & 6 & $2,3,1$ & $3,4,5$ & $3,3,3$ & $1,1,4$ & $3,3,3$ & \\
\hline 6 & $3-4$ & 3 & $2,2,2$ & $2,2,2$ & $3,3,3$ & $0,0,0$ & $3,3,3$ & \\
\hline 7 & $3-1$ & 3 & $2,2,2$ & $3.3,3$ & $2,2,2$ & 1. 1, 1 & $2,2,2$ & \\
\hline 8. & $3-4$ & 1 & $2,2.2$ & $3,5,5$ & $2,2,2$ & $2,3,3$ & $2,2, ?$ & \\
\hline 9 & $4-5$ & 2 & $2,2,2$ & $3,2,5$ & $2,2,1$ & $1.0,3$ & $2,2,2$ & $\begin{array}{l}\text { Litlay activity } 4-5 \text {, } \\
\text { one time slice. }\end{array}$ \\
\hline 10 & $\begin{array}{l}1-5 \\
1-6\end{array}$ & $\begin{array}{l}2 \\
4\end{array}$ & $\begin{array}{l}2,2,2 \\
1,2,2\end{array}$ & $\begin{array}{lll}2, & 2, & 2 \\
0 ; & 0 ; & 0\end{array}$ & $1,1,1$ & $\begin{array}{lll}0, & 0,0 \\
0, & 0, & 0\end{array}$ & $1,2,13$ & \\
\hline 11 & $\begin{array}{l}4-6 \\
5-6\end{array}$ & $\begin{array}{l}4 \\
3\end{array}$ & $\frac{1}{2}, \frac{1}{2}, \frac{1}{2}$ & $\begin{array}{l}\text { 2. 2, } 2 \\
\text { 1. } 1,1\end{array}$ & $\frac{1}{1}, 1,1,1$ & $\frac{1}{0}, \frac{1}{0}, \frac{1}{0}$ & 1., $\frac{1}{0}, \frac{1}{0}$ & \\
\hline 12 & $4-6$ & 4 & $1,1,1$ & $2,2,2$ & $0,0,0$ & $1,1,1$ & $0,0,0$ & $\begin{array}{l}\text { Poatpone activity } \\
5-6 \text { for the first } \\
\text { time glice. }\end{array}$ \\
\hline 14 & $5-6$ & 3 & $\begin{array}{l}1,2,1 \\
2,2,2\end{array}$ & $\begin{array}{l}2,2,2 \\
2,2,2\end{array}$ & $0,0,0$ & $\begin{array}{l}1,1,1 \\
0,0,0\end{array}$ & $\begin{array}{l}0,0,0 \\
2,2,2\end{array}$ & $\begin{array}{l}\text { Time ollce } \\
\text { Poatpone aetivity } \\
5-6 \text { for the gecond } \\
\text { time ollce }\end{array}$ \\
\hline
\end{tabular}

M.B. R.Req. : Activity Resource Requiremert

P.R.A. : Primary Reaource Avallabliltiea

S.R.A. : Secondary Resource Avallabllit1es

P.R.R.: Primery Ramaining Resourca

S.K.M. : Secondary Remalning Rebources

k. Type I Resoure

$\mathrm{R}_{2}$ : Type 2 Resource

$\mathrm{A}_{3}$ : Typo 3 Recouree

Table (2) Output Schedule Results (Priority Rule: CPM Float) 


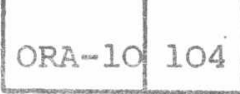

LIR'S'I A.M.E. CONFERENCE

29-31 May 1984, Cairo

\section{REFERENCES}

1- Batterby, A. : "Network Analysis for Planning and Scheduling". MeMilian, London, 1970.

2- Cooper, D.F. : "Heuristics for Scheduling Resource Constrained Projects: An Experimental Investigation"。 Ranagement Science, Vol. 22, No.11 July, 1976.

3- Elmaghraby, S.E. : "The Design Of Production Systems". keinhold, New York, 1966.

4- EImaghraby, S.E. : "Activity Networks: Project Planning and Control by Network Models". John Wiley \& Sons Inc, New York, 1977.

5- IBM Application Program: Project Analysis and Control System (PROJACS) - CeneraI Information.

Manual, Program No. 5746-XPI (D05/VS)

GH $19-1055-3$, 1978.

6- Kurtulus, I. and E.W.Davis : "Multi-Project Scheduling: Categorization of Heuriatic Rules Performance". Management Science, Vol.28, No. 2, Feb., 1982.

To Weist, J.D. : "Some Properties of Schedules for Large Projects with Limited Resources". Oper. Res., Vol. 12, No. 3, 2964. 